\title{
Comparative Study on Bubble Deck Slab and Conventional Reinforced Concrete Slab - A Review
}

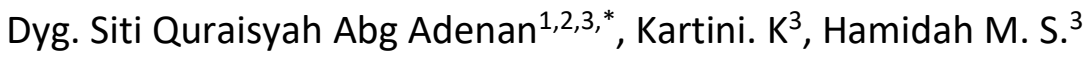 \\ 1 I-Geo Disaster Research Centre, Infrastructure University Kuala Lumpur (IUKL), 43000 Kajang, Selangor, Malaysia \\ 2 Department of Civil Engineering and Construction, Faculty of Engineering, Science and Technology (FEST), Infrastructure University Kuala \\ Lumpur (IUKL), 43000 Kajang, Selangor, Malaysia \\ 3 Faculty of Civil Engineering, University Teknologi MARA (UiTM), 40450 Shah Alam, Selangor, Malaysia
}

\section{ABSTRACT}

\begin{abstract}
Slab is the most important structural member of any building structure and also one of the largest member consuming concrete. Thus, the alternative biaxial hollow slab system known as bubble deck slab had been introduced as one of the effective slab systems that improves building design and performance while reduce the self-weight by eliminating concrete part in the middle of conventional slab which does not contribute to the structural performance. The effective hollow slab systems that dramatically reduce the slab weight by $30-50 \%$. Moreover, concrete usage is reduced as $1 \mathrm{~kg}$ of recycled plastic replaces $100 \mathrm{~kg}$ of concrete. The new prefabricated construction technology using bubble deck slab is recently applied in many industrial projects in the world. It has many advantages as compared to conventional reinforced concrete slab such as lower total cost, reduced material use, enhanced structural efficiency, decreased construction time, and is a green. The aim of this paper is to discuss the significance and various properties of bubble deck slab against conventional reinforced concrete slab based on various studies and researches that had been done.
\end{abstract}

Keywords:

Slab, Bubble Deck Slab, Conventional

Reinforced Concrete Slab

Copyright @ 2020 PENERBIT AKADEMIA BARU - All rights reserved

\section{Introduction}

Slab is the most important structural member of any building structure and also one of the largest member consuming concrete. When the load acting on slab or clear span between column is large, the deflection of the slab will also become large. Thus, the thickness of slab is on increasing. The increasing of slab thickness will cause the slabs heavier due to the increasing of slab self-weight. Thus, column and foundation size will also become increase which needs more building materials consumption such as concrete and steel reinforcement [2]. Therefore, the new prefabricated construction technology using high density polyethylene (HDPE) bubble deck slab is recently applied in many industrial projects in the world. The first biaxial hollow slab or also known as bubble deck slab is the invention of Jorgen Bruenig from Denmark in 1990's. HDPE bubble deck slab uses hollow balls made by recycled plastic and therefore it is an innovatory method of virtually eliminating the

\footnotetext{
* Corresponding author.

E-mail address: dyg_quraisyah@iukl.edu.my
}

https://doi.org/10.37934/arms.70.1.1826 
concrete part in the middle of conventional slab which does not contribute to the structural performance $[3,9,11,12]$.

The invention of bubble deck slab will dramatically reduce structural dead weight by linking air and steel reinforcement directly. It has many advantages as compared to traditional concrete slab such as lower total cost, reduced material use, enhanced structural efficiency, decreased construction time, and is a green. bubble deck is a unique system that is radically improves building design and performance while reducing the overall cost by eliminating concrete dead weight at the middle of a floor slab $[2,9,11]$. Study conducted showed that concrete consumption is reduced as 1 $\mathrm{kg}$ of recycled plastic bubble replaces $100 \mathrm{~kg}$ of concrete $[9,11]$. Thus, reduce the cement production and allows reduction in global carbon dioxide (CO2) emissions [14].

Hence, this technology is environmentally green and sustainable [6]. For every $5000 \mathrm{~m} 2$ of bubble deck slab, the company or owner can prevent 278 tonnes of $\mathrm{CO} 2$ emission that comes from concrete usage and saves 1745 Gigajoule of energy used to manufacture and transport concrete. Moreover, by using less concrete, carbon in the slab can be saved up to $40 \%$. Carbon emissions from transportation and equipment usage will also decrease with the use of fewer materials. Additionally, the consumption HDPE bubbles can be salvaged and reused for other projects, or can be recycled [1].

Therefore, the aim of this paper is to discuss the significance and various properties of bubble deck slab against conventional reinforced concrete slab based on various studies and researches that had been done.

\section{Literature Review}

Ibrahim et al. [15] studied on flexural behaviors of two-way slab, a conventional reinforced concrete (RC) slab and four bubble deck slabs having void diameter to slab thickness ratios of 0.51 , 0.64 and 0.80 . Two dimensional flexural tests were conducted by using special loading frame in order to verify the flexural behaviour of bubble deck slab in term of ultimate load, deflection, concrete compressive strain and crack pattern. Results have shown that the flexural behavior of bubble deck slab depend on the void diameter to slab thickness ratio. The ultimate load capacities for bubble deck slabs having bubble diameter to slab thickness of 0.51 and 0.64 were the same of solid slabs, while when bubble diameter to slab thickness of 0.80 the ultimate capacities were reduced by about $10 \%$. The deflections under service load of bubble deck specimens were a little higher than conventional RC slab. The bubble deck specimens exhibited smaller stiffness with increasing load and after yielding of reinforcing bars, strength and stiffness of the bubble deck specimens were smaller compared to the conventional RC slab. The concrete compressive strain of bubble deck specimens is greater than that conventional RC slab due to concrete volume reduction in the compression zone. All specimen for conventional RC slab and bubble deck slab showed flexural failure mode with diagonal flexural cracks and some small longitudinal cracks appeared in specimens with bubble diameter to slab thickness of 0.80 .

Shetkar and Hanche [9] reported that the bubble deck improved flexural capacity, stiffness and shear capacity of at least $70 \%$ when the same amount of concrete and the same reinforcement is used as in the conventional RC slab. Different bubble diameter between $180 \mathrm{~mm}$ to $450 \mathrm{~mm}$ with the slab depth from $230 \mathrm{~mm}$ to $600 \mathrm{~mm}$ were used in their study. It was resulted that, behaviour of bubble deck slabs is influenced by the ratio of bubble diameter to slab thickness. Besides, it was found that $30-50 \%$ concrete economy than conventional RC slab. Concrete usage is reduced as $1 \mathrm{~kg}$ of recycled plastic replaces $100 \mathrm{~kg}$ of concrete. Thus, reduce dead weight up 50\% which allow creating foundation size smaller and lead the construction time become faster due to reduction of material 
consumption. Therefore, cement production can be reduced and allows reduction in global $\mathrm{CO} 2$ emissions. Hence, this bubble deck technology is environmentally green and sustainable.

Surendar and Ranjitham [10] did the experimental and numerical study on bubble deck slab with the aim of reducing the amount of concrete in the middle of the slab by using hollow balls made by recycled plastic. The numerical Finite Element Analysis Software ANSYS had been carried out to study structural behaviour of the slab. It was reported the technology of bubble deck slab is an alternatives method which does not contribute to the structural self-weight and also leads to 30 to $50 \%$ lighter slab reduces the loads on the columns, walls and foundation, and also the entire building. The conventional RC slab carried the load of $365 \mathrm{kN}$ and causes the deflection of about $14.46 \mathrm{~mm}$. The bubble deck slab carried the load of $341.5 \mathrm{kN}$ and causes the deflection of about $18.56 \mathrm{~mm}$. Crack occurs at side face of the slab due to bending. The bubble deck slab can withstand $75 \%$ of loading carrying capacity when compared to conventional RC slab. $45.238 \mathrm{Kg}$ of concrete can be eliminated from $1000 \mathrm{~mm} \times 1000 \mathrm{~mm} \times 150 \mathrm{~mm}$ of slab by using $100 \mathrm{~mm}$ ball which results in reduction in weight of slab. Bubble deck slab is better in stress criteria and its weight than that of conventional RC slab.

Mushfiq et al. [7] studied the loadbearing capacity of bubble deck slab and compare with conventional RC slab with different bubble diameter to slab thickness ratios (B/H). M30 grade of concrete and $150 \mathrm{~mm}$ thickness were designed and used in their study. Three slabs were casted, one conventional slab and another two slab with bubbles consist of two different bubble diameter size which were $90 \mathrm{~mm}$ and $120 \mathrm{~mm}$. The bubble deck with two different $(\mathrm{B} / \mathrm{H})$ ratios which were 0.60 and 0.80 designated as BD1 and BD2. The conventional slab was casted without bubble with 183.35 $\mathrm{kg}$ of concrete while BD1 and BD2 were casted with $164 \mathrm{~kg}$ and $151.54 \mathrm{~kg}$ of concrete having 35 and 16 spherical balls respectively. The conventional slab carried a load of $429.2 \mathrm{KN}$ and cause $12.26 \mathrm{~mm}$ deflection with crack occurring after a load of $164 \mathrm{KN}$. BD1 slab with B/H ratio of 0.6 carried a total load of $350.78 \mathrm{KN}$ and caused $12.6 \mathrm{~mm}$ deflection with crack occurring after a load of $158 \mathrm{KN}$ while the BD2 slab with $\mathrm{B} / \mathrm{H}$ ratio of 0.8 carried a total load of $398.2 \mathrm{KN}$ and causes $13.2 \mathrm{~mm}$ deflection with crack occurring after a load of $123 \mathrm{KN}$. According to their study, it was reported that the stiffness reduction of 0.891 and 0.773 while the weight reduction of $10.55 \%$ and $17.43 \%$ in the BD1 and BD2 slabs compared to the conventional RC slab as shown in Table 1. Thus, this an added advantage for the bubble deck slabs especially in structures where load is an issue.

Table 1

Stiffness reduction and weight saving [7]

\begin{tabular}{cccccc}
\hline $\begin{array}{c}\text { Slab thickness } \\
(\mathrm{h}) \mathrm{mm}\end{array}$ & $\begin{array}{c}\text { Ball diameter } \\
(\mathrm{d}) \mathrm{mm}\end{array}$ & $\begin{array}{c}\text { Moment of } \\
\text { inertia } \\
\text { of solid section } \\
\text { Is }\end{array}$ & $\begin{array}{c}\text { Moment of } \\
\text { inertia } \\
\text { of voided } \\
\text { section IV }\end{array}$ & $\begin{array}{c}\text { Stiffness } \\
\text { reduction }\end{array}$ & $\begin{array}{c}\% \\
\text { weight } \\
\text { saving }\end{array}$ \\
\hline \multirow{2}{*}{150} & 90 & $2.98 \times 107$ & $3.2 \times 106$ & 0.891 & 10.55 \\
\hline
\end{tabular}

Bhade and Suryawanshi [2] studied on the structural behavior on two way bubble deck slab using hollow spherical balls. The experimental work were conducted by casting and testing the conventional slab and bubble deck slab with various bubbles arrangement which is continuous arrangement of bubbles within whole slab and two types of alternative bubbles arrangement in the slab. According to their study, that the concrete volume of bubble deck (continuous) is reduced so that weight of slab ultimately decrease and simultaneously the load carrying capacity has also increase as compare to conventional slab. However, the arrangement of the bubbles can effect on the load carrying capacity of the slab where the load carrying capacity for alternative arrangement of bubbles were increased than conventional slab but less than continuous bubble deck slab. The 
quantity of bubbles in slab also affect on the elasticity property. Thus, bubble deck slab has improve the elasticity property of slab as conventional slab is $6 \%$ less deflect than bubble deck. Other than that, the weight of the conventional slab is higher $33 \%$ than the bubble deck slab. It was reported that the load, deflection and weight parameters give better result for bubble deck slab as compared to conventional slab.

Ali and Kumar [1] studied on behavioral analysis of conventional slab and bubble deck slab using ANSYS workbench 14.0. It was reported that bubble deck slab performed better than a conventional solid concrete. Due to the decreased dead load from the use of HDPE spheres in concrete, the maximum stresses and internal forces in the voided deck about to $40 \%$ less than the solid slab. Their investigation has proven that the bubble beck is more efficient than a conventional concrete slab in all aspects. Moreover, the finite element analysis of models of the slabs also verified the prior analysis and experiments.

Nagashree et al. [8] did the comparative studies of conventional slab and bubble deck slab based on stiffness and economy. Based on their study, the stiffness of bubble deck slab with smaller diameter balls size of $60 \mathrm{~mm}$ was found to be greater than that of $70 \mathrm{~mm}$ diameter ball slab and conventional slab. It was reported that the concrete slab for $60 \mathrm{~mm}$ diameter ball was found to be more economical than concrete slab containing $70 \mathrm{~mm}$ diameter ball as about $14 \%$ of money can be saved by using bubble deck slab of $60 \mathrm{~mm}$ diameter and $9.41 \%$ by $70 \mathrm{~mm}$ diameter. Thus, the bubble deck slab of $60 \mathrm{~mm}$ diameter is more effective in terms of strength, stiffness and economy compared to conventional slab. Stiffness and percentage reduction in concrete cost for conventional and bubble deck slabs of their study are presented in Table 2.

\section{Table 2}

Stiffness and percentage reduction in concrete cost for conventional slabs and bubble deck slabs [8]

\begin{tabular}{ccc}
\hline Slab designation & $\begin{array}{c}\text { Stiffness } \\
\text { (KN/mm2) }\end{array}$ & $\begin{array}{c}\text { Percentage reduction } \\
\text { in cost of concrete }\end{array}$ \\
\hline Conventional slab & 17.30 & - \\
\hline Bubble deck slab (70mm dia) & 13.18 & $9.41 \%$ \\
\hline Bubble deck slab (60mm dia) & 21.42 & $14.10 \%$ \\
\hline
\end{tabular}

The economic savings as a result of bubble deck is not only obtained by the deck itself. The largest savings are obtained through reductions and simplifications throughout the entire construction [5]. The comparison of conventional concrete slab and bubble deck slab as shown in Table 3.

- Savings in materials (slabs, beams, columns, foundations) are substantial (up to $50 \%$ ).

- Transportation costs are substantially reduced

- Faster construction time; easy carrying out (reduction in erection cycle with $20-40 \%$ )

- Subsequent faster installation of mechanical and electrical services

- Buildings are lighter than conventional slab design therefore, lower overall costing

- Buildings can made more flexible, and changes are much less costly.

- Less weather dependent

- Less Concrete $35 \%$. Saving of up to $40 \mathrm{~kg} \mathrm{CO}^{2} / \mathrm{m}^{2} .50,000 \mathrm{~m}^{2}$ building can save up to 2,000 tons of $\mathrm{CO}^{2}$.

- Less workers required. Virtually no carpentry, no rebars beams, less skill workers needed, less placement of reinforcement.

- Less transportation of construction materials. Less crowded construction area. Less steel bars, less concrete, virtually no plywood, less false ceiling. 
- All saving effects combined may offer a savings potential of $5-15 \%$ of the carcase.

Table 3

Comparison of conventional concrete slab and bubble deck slab [5]

\begin{tabular}{ccccccc}
\hline Slab designation & $\begin{array}{c}\text { Slab } \\
\text { depth } \\
(\mathbf{m m})\end{array}$ & $\begin{array}{c}\text { Site } \\
\text { concrete } \\
\text { volume } \\
\left(\mathbf{m}^{\mathbf{2}} / \mathbf{m}^{\mathbf{3}}\right)\end{array}$ & $\begin{array}{c}\text { Site } \\
\text { concrete } \\
\text { Quantity } \\
\left(\mathbf{m}^{\mathbf{2}}\right)\end{array}$ & $\begin{array}{c}\text { Total slab } \\
\text { death load } \\
\text { (Tonnes) }\end{array}$ & $\begin{array}{c}\text { Embodied } \\
\text { energy } \\
\text { (Giga joules) }\end{array}$ & $\begin{array}{c}\mathrm{CO}_{2} \\
\text { emissions } \\
\text { (Tonnes) }\end{array}$ \\
\hline Solid slab & 310 & 0.31 & 1.395 & 3376 & 3278 & 125 \\
\hline Bubble deck slab & 230 & 0.11 & 495 & 1758 & 1707 & 65 \\
\hline BD saves & 80 & 0.20 & 900 & 1618 & 1571 & 60 \\
\hline
\end{tabular}

\section{Conventional and Bubble Deck Slab}

\subsection{Materials Preparation}

\subsubsection{Bubble}

According to Ibrahim et al. [15], the plastic spheres with different diameters of $64 \mathrm{~mm}$ and 80 $\mathrm{mm}$ that had been used in their project were manufactured at Al-Sabah factory in Iraq while according to Mushfiq et al. [7] the plastic spheres with different diameter size of $90 \mathrm{~mm}$ and $120 \mathrm{~mm}$ used in their project were manufactured in Sadar bazar Delhi, India at Popli Enterprises factory. Recycled plastic were used in order to curb consumption of finite natural resources such as oil and minimize the burden on the environment through the cyclical use of resources. Thus, recycling martial reduces inputs of new resources and limits the burden on the environment and reduces the risks to human health $[7,10,15]$.

Generally recycled plastic balls are used, because to reduce wastage of plastics instead of burning the plastics and also to reduce the environmental pollution. The cost of plastic ball is low when compared to the HDPE. The Bubble Deck slabs being entirely recyclable. The plastic ball does not react chemically with the concrete or the reinforcement, it has no porosity and has enough rigidity and strength to take more loads while pouring of the concrete. The size of the recycled polyethylene hollow spheres is about $100 \mathrm{~mm}$ diameter [10].

According to Shetkar and Hanche [9] and Mirajkar et al. [6] the bubbles are made using high density polypropylene materials. These are usually made with nonporous material that does not react chemically with the concrete or reinforcement bars. The bubbles have enough strength and stiffness to support safely the applied loads in the phases before and during concrete pouring. Bubble diameter varies between $180 \mathrm{~mm}$ to $450 \mathrm{~mm}$ which is depending on the slab depth from $230 \mathrm{~mm}$ to $600 \mathrm{~mm}$. The distance between bubbles must be greater than $1 / 9$ th of bubble diameter. The nominal diameter of the gaps was $180,225,270,315$ or $360 \mathrm{~mm}$. The bubbles used were spherical and ellipsoidal in shape.

\subsubsection{Steel Reinforcement}

Different sizes of reinforcing bars, 4 and $5 \mathrm{~mm}$ were used in the specimens [15]. High grade steel of Fe 550 or Fe 500 is generally used. The same grade of steel is used in both in top and bottom steel reinforcement. $10 \mathrm{~mm}$ diameter steel bar is used for main reinforcement and $8 \mathrm{~mm}$ diameter steel bar is used for distributor reinforcement. Reinforcement provided in both transverse and longitudinal direction in the form of welded mesh [10]. High grade steel of Fe 500 is generally used. The same grade of steel is used in both in top and bottom steel reinforcement. Here $8 \mathrm{~mm}$ diameter steel bar is used for main reinforcement and distributor reinforcement. Reinforcement provided in both 
transverse and longitudinal direction. $4 \mathrm{~mm}$ diameter steel was welded to keep distance B/W top and bottom reinforcement [7].

The reinforcement of the plates is made of two meshes, one at the bottom part and one at the upper part that can be tied or welded. The steel is fabricated in two forms - the meshed layers for lateral support and diagonal girders for vertical support of the bubbles. The distance between the bars are corresponding to the dimensions of the bubbles that are to be used and the quantity of reinforcement from transverse ribs of the slab $[6,9]$.

\subsubsection{Concrete}

According to Ibrahim et al. [15], the concrete mix design with compressive strength of 33MPa was used. The maximum size of aggregate used in this study was $10 \mathrm{~mm}$ and the concrete mixture proportions are presented in Table 4.

Table 4

\begin{tabular}{cccccc}
\multicolumn{6}{l}{ Concrete Mixture Design [15] } \\
\hline Designation & $\begin{array}{c}\text { Cement } \\
\left(\mathrm{kg} / \mathrm{m}^{3}\right)\end{array}$ & $\begin{array}{c}\text { Water } \\
\left(\mathrm{kg} / \mathrm{m}^{3}\right)\end{array}$ & $\begin{array}{c}\text { Fine Aggregate } \\
\left(\text { Sand) }\left(\mathbf{k g} / \mathrm{m}^{3}\right)\right.\end{array}$ & $\begin{array}{c}\text { Coarse } \\
\left(\mathbf{k g} / \mathrm{m}^{3}\right)\end{array}$ & $\begin{array}{c}\text { w/c Ratio to Give } \\
\text { Slump } \\
\mathbf{1 4 0 \pm 1 0 \%}\end{array}$ \\
\hline C33 & 425 & 225 & 735 & 1015 & 0.53 \\
\hline
\end{tabular}

Standard Portland cement is commonly used and no plasticizer is needed. Mix design procedure based on the grade used. The concrete used for the precast layer can be of common concrete or selfcompacting concrete. Minimum grade of concrete should not be less than M30 and the depth of the slab is about $150 \mathrm{~mm}$. Conventional concrete was poured and casted in Bubble Deck slab is shown in Figure 1 [10].

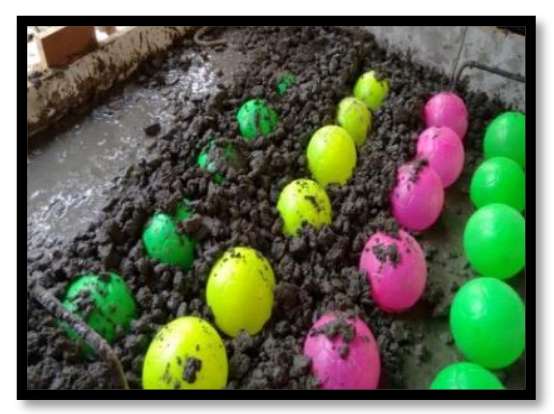

Fig. 1. Conventional Concrete in Bubble Deck Slab [10]

The concrete used for joint filling in the Bubble Deck floor system must be above class 20/25. Usually self-compacting concrete is used, either for the casting of prefabricated filigree slab, or for the joint filling on the site. Self-compacting concrete can be poured into forms, flow around congested areas of reinforcement and into tight sections, allow air to escape and resist segregation. The nominal maximum size of the aggregate is the function of thickness of the slab. The size should be less than $15 \mathrm{~mm}$ and M30 Grade and above should be used $[6,9]$.

Ordinary Portland cement of grade 43 confirming to IS 8112-1989 as a hydrated paste is being used as the binder of concrete. The specific gravity of cement calculated by the use of specific gravity 
bottle was found out to be 3.14. Natural river sand size $4.75 \mathrm{~mm}$ and below confirming to zone 3 of IS 383-1970 is being used as the fine aggregate while natural crushed stone with size $20 \mathrm{~mm}$ is being used as coarse aggregate [7].

\subsection{Set-up of Conventional and Bubble Deck Slab}

Table 5 shows the sample description for conventional slab and bubble deck slab while Figure 2 (a), Figure 2(b) and Figure 2(c) show the conventional slab, bubble deck slab 1 (BD1 slab) and bubble deck slab 2 (BD2 slab) that had been prepared for experimental studies in accordance to Mushfiq et al., [7].

\section{Table 5}

Sample description for conventional slab and bubble deck slab [7]

\begin{tabular}{|c|c|c|c|c|c|c|c|c|c|}
\hline No & $\begin{array}{l}\text { Specimen } \\
\text { name }\end{array}$ & $\begin{array}{l}\text { Length } \\
\text { (mm) }\end{array}$ & $\begin{array}{l}\text { Width } \\
\text { (mm) }\end{array}$ & $\begin{array}{c}\text { Slab } \\
\text { Thickness, } \\
\text { H (mm) }\end{array}$ & $\begin{array}{c}\text { Bubble } \\
\text { Diameter, } \\
\text { B (mm) }\end{array}$ & $B / H$ & $\begin{array}{c}\text { No. of } \\
\text { plastic } \\
\text { spheres }\end{array}$ & $\begin{array}{c}\text { Fc } \\
\text { (Mpa) }\end{array}$ & $\begin{array}{c}\text { Fy } \\
\text { (Mpa) }\end{array}$ \\
\hline 1 & $\begin{array}{c}\text { Conventional } \\
\text { Slab }\end{array}$ & \multirow{3}{*}{700} & \multirow{3}{*}{700} & \multirow{3}{*}{150} & - & - & - & \multirow{3}{*}{33.6} & \multirow{3}{*}{500} \\
\hline 2 & BD1 & & & & 90 & 0.6 & 35 & & \\
\hline 3 & BD2 & & & & 120 & 0.8 & 16 & & \\
\hline
\end{tabular}

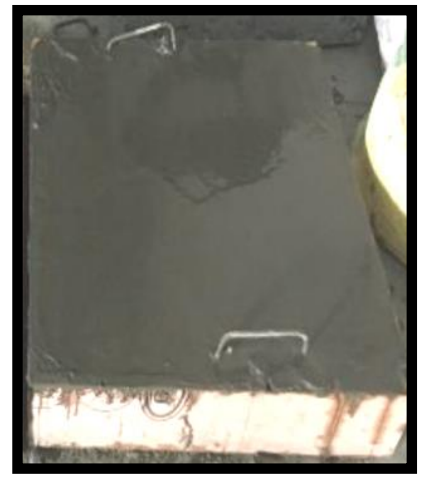

(a)

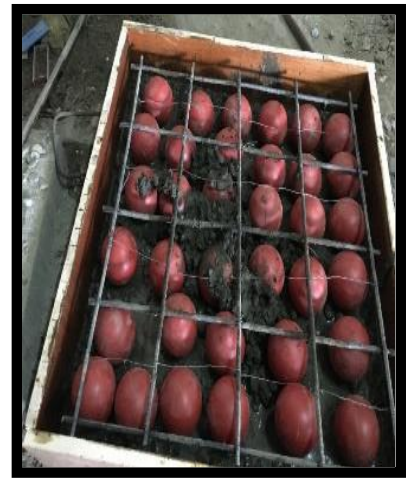

(b)

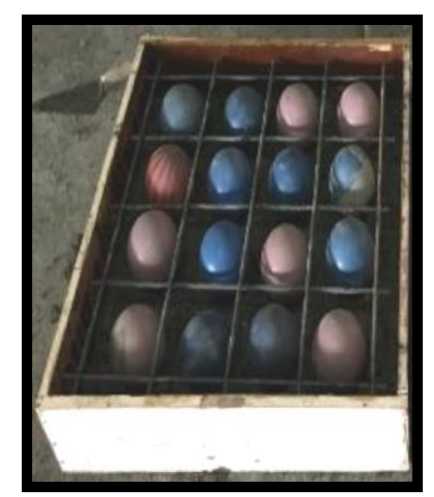

(c)

Fig. 2. (a) Conventional slab; (b) BD1 slab; (c) BD2 slab

In accordance to slab set-up conducted by Bhade and Suryawanshi [2], Figure 3 shows the reinforcement set up for conventional slab while Figure 4 shows the reinforcement set up for bubble deck slab. The reinforcement mesh is placed both side of the bubbles and bubbles are arranged in continuous manner as shown in Figure 5 . The reinforcement mesh for alternative bubble deck slab (type I) is placed both side of the bubble and bubbles are placed in every row and column in alternate way as shown in Figure 6 while the reinforcement mesh for alternative bubble deck slab (type II) is placed both side of the bubble and bubbles are placed in alternate row and in every column as shown in Figure 7. 


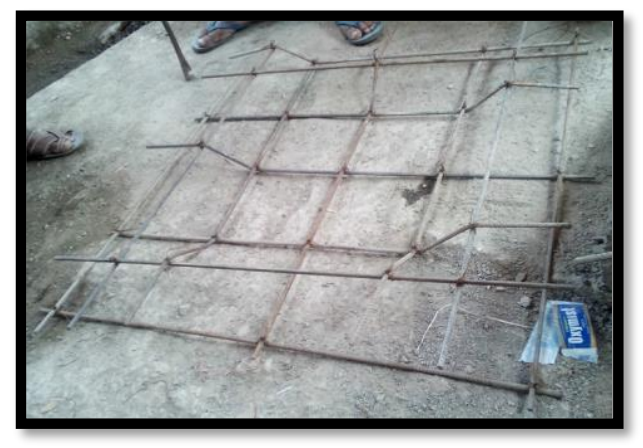

Fig. 3. Reinforcement of conventional slab

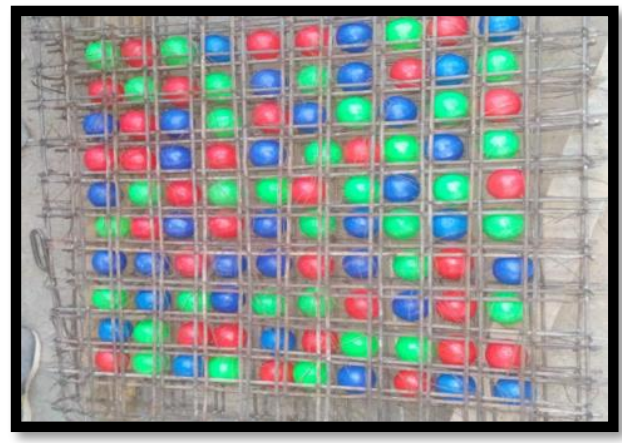

Fig. 5. Continuous bubble deck slab

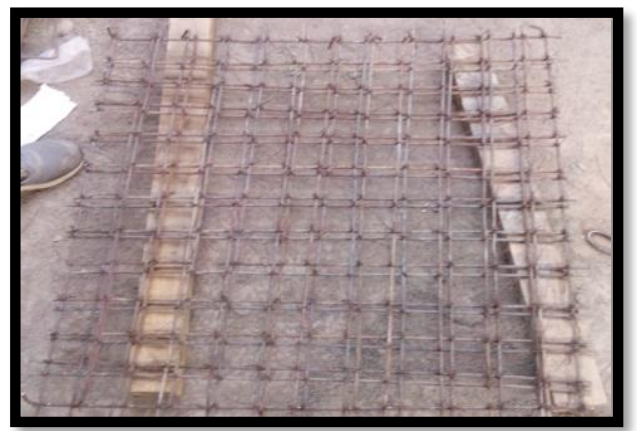

Fig. 4. Reinforcement of bubble deck slab

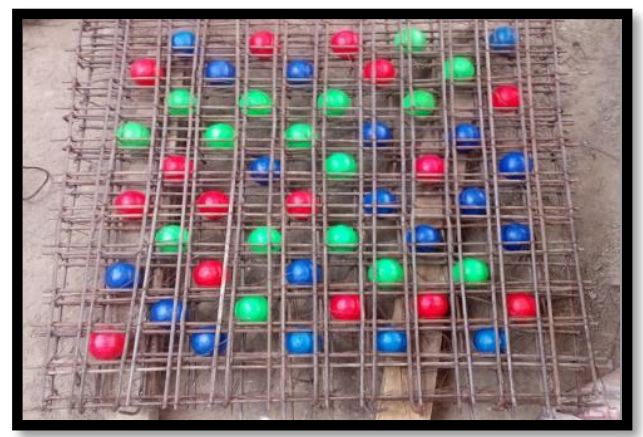

Fig. 6. Alternative bubble deck slab (Type I)

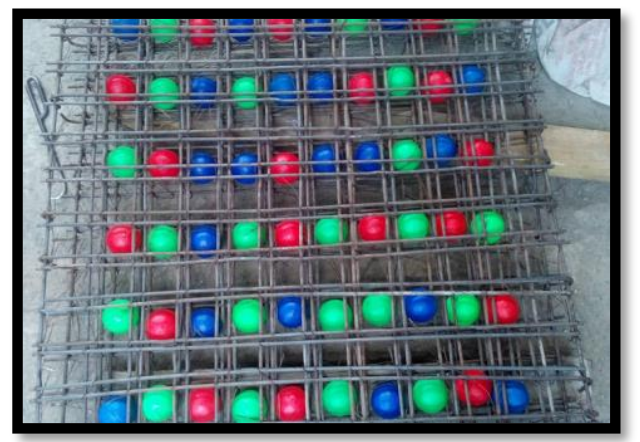

Fig. 7. Alternative bubble deck slab (Type I)

\section{Conclusion}

Based on the review of literature, the following conclusions are outlined:

1. The bubble deck configuration gives much improved flexural capacity, stiffness and shear capacity of at least $70 \%$ when the same amount of concrete and the same reinforcement is used as in the solid slab, realizing $30-50 \%$ concrete economy, in comparison with the solid slab.

2. The load and deflection give better result for bubble deck slab as compared to conventional slab. 
3. Concrete usage is reduced as $1 \mathrm{~kg}$ of recycled plastic replaces $100 \mathrm{~kg}$ of concrete. This avoids the cement production and allows reduction in global $\mathrm{CO}^{2}$ emissions. Hence this technology is environmentally green and sustainable.

4. Advantage of bubble deck system is the significant cost saving, because of the possibility of obtaining great spans with less support elements.

5. Reducing material consumption made it possible to make the construction time faster, to reduce the overall costs. Besides that, it has led to reduce dead weight up to $50 \%$, which allow creating foundation sizes smaller.

\section{Acknowledgement}

Thank you to Institute of Research Management \& Innovation (IRMI), UiTM for the Research Entity Initiative (REI) [600-IRMI/MYRA 5/3/REI (001/2018)] Grant provided, Faculty of Civil Engineering, Universiti Teknologi MARA (UiTM) and Department of Civil Engineering and Construction, Infrastructure University Kuala Lumpur (IUKL) for the support in making this research a success.

\section{References}

[1] Ali, Sameer, and Manoj Kumar. "ANALYTICAL STUDY OF CONVENTIONAL SLAB AND BUBBLE DECK SLAB UNDER VARIOUS SUPPORT AND LOADING CONDITIONS USING ANSYS WORKBENCH 14.0." (2017).

[2] Bhade, Bhagyashri G., and Y. R. Suryawanshi. "Structural behavior on two way Bubble Deck slab using hollow Spherical balls." VJER-Vishwakarma Journal of Engineering Research, 1(2), 116-124.

[3] Bhowmik, Rittik, Sourish Mukherjee, Aparna Das, and Sulagno Banerjee. "Review on Bubble deck with spherical hollow balls." International Journal of Civil Engineering and Technology (IJCIET) Volume 8.

[4] BubbleDeck Construction Sdn Bhd. (n.d.). Retrieved from http://www.bubbledeck.com.my/tech-concept.html.

[5] Flexural Capacities of Reinforced Concrete Two-Way Bubbledeck Slabs of Plastic Spherical Voids

[6] Mirajkar, S., Balapure, M., \& Management, E. "Study of Bubble Deck Slab", International Journal of Research In Science \& Engineering 7 (2017): 1-5.

[7] Mushfiq, M. S., Saini, S., \& Rajoria, N. “Experimental Study on Bubble Deck Slab”, International Research Journal of Engineering and Technology (IRJET) 4, no. 5 (2017): 1000 - 1004.

[8] Nagashree B, Hokrane, S., \& Saha, S. Comparative Studies on Conventional Slab and Bubble Deck Slab Based on Stiffness and Economy. International Journal for Scientific Research \& Development 5, no. 3, (2017): 1396 - 1398.

[9] Shetkar, Arati, and Nagesh Hanche. "An experimental study on bubble deck slab system with elliptical balls." Indian Journal of Scientific Research (2015): 21-28.

[10] Surendar, M., Ranjitham, M. (2006). Numerical and Experimental Study on Flexural-Torsional 23, no. 10: 312-318.

[11] Tiwari, N., and S. Zafar. "Structural behaviour of bubble deck slabs and its application: main." IJSRD Int. J. Sci. Res. Dev 4, no. 02 (2016): 2321-0613.

[12] Vakil, R. R., \& Madhuri Nilesh, M. (2017). Comparative Study of Bubble Deck Slab and Solid Deck Slab - A Review, 383-392.

[13] Retrieved from http://data.conferenceworld.in/IETEOCTOBER2017/28.pdf

[14] Worrell, Ernst, Lynn Price, Nathan Martin, Chris Hendriks, and Leticia Ozawa Meida. "Carbon dioxide emissions from the global cement industry." Annual review of energy and the environment 26, no. 1 (2001): 303-329.

[15] Ibrahim, Amer M., Nazar K. Ali, and Wissam D. Salman. "Flexural capacities of reinforced concrete two-way bubbledeck slabs of plastic spherical voids." Diyala Journal of Engineering Sciences 6, no. 2 (2013): 9-20. 